\title{
Urban home gardens in the Global North: A mixed methods study of ethnic and migrant home gardens in Chicago, IL
}

\author{
John R. Taylor ${ }^{1 \star}$ and Sarah Taylor Lovell ${ }^{2}$ \\ ${ }^{1}$ University of Illinois at Urbana-Champaign, Department of Crop Sciences, 1105 Plant Sciences Lab, Urbana, \\ Illinois, USA \\ ${ }^{2}$ University of Illinois at Urbana-Champaign, Department of Crop Sciences, Urbana, Illinois, USA \\ *Corresponding author: jrtaylo2@illinois.edu
}

\section{Accepted 9 April 2014;}

From the Field for Themed Content: Urban Agriculture

\begin{abstract}
In the United States, interest in urban farms and community gardens is flourishing, yet the urban home food garden (UHFG) and its contributions to urban systems have been overlooked and understudied. To begin to address this gap, we are conducting a mixed methods study of African American, Chinese-origin and Mexican-origin households with home gardens in Chicago, IL. Study methods include in-depth interviews, participant observation, ethnobotanical surveys and analysis of the chemical and physical properties of garden soils. As of this writing, findings indicate that home gardening has an array of beneficial effects, contributing to household food budgets and community food systems, the reproduction of cultural identity and urban biodiversity. The majority of informants in the study were internal or international migrants. For these individuals, gardening, culture-specific food plant assemblages and the foodways they support represent a continuation of cultural practices and traditional agroecological knowledge associated with their place of origin. The gardens of some migrant households also harbor urban agrobiodiversity with roots in the Global South. At the same time, gardens may have less salubrious effects on urban systems and populations. A lack of knowledge of safe gardening practices may expose vulnerable populations to environmental hazards such as soil contaminants. Gardeners in this study reported using synthetic chemical fertilizers and pesticides, sometimes indiscriminately, and the repeated application of synthetic fertilizers and compost may contribute to the nutrient loading of urban stormwater runoff. These effects may be moderated by the relatively low bulk density and high porosity of garden soils due to tillage and the application of organic matter, which can be expected to enhance stormwater infiltration. While the UHFG's potential contributions to urban systems are significant, outreach and research are needed to help gardeners grow food safely and sustainably in ways that contribute to overall ecosystem health.
\end{abstract}

Key words: urban agriculture, home garden, food security, ecosystem services, Global North

\section{Introduction}

The home food garden represents a major lacuna in the rapidly expanding academic literature on urban agriculture in the developed world. A recent review of the peerreviewed literature on community gardens, for example, identified 46 studies of such gardens in the United States ${ }^{1}$. A comparable search on Google Scholar for studies of US home food gardens yielded only five results, including: two quantitative analyses of the spatial distribution of urban food gardens, including home gardens, in Chicago, Illinois ${ }^{2}$ and Madison, Wisconsin ${ }^{3}$; a socio-demographic analysis of survey data from rural, suburban and urban households with food gardens in the state of $\mathrm{Ohio}^{4}$; a qualitative study of Vietnamese home gardeners in Louisiana ${ }^{5}$; and a study of households participating in a home gardening program in San Jose, $\mathrm{CA}^{6}$. What do we know about home food gardens suggests they make a substantially larger contribution to the total area of urban food production than the public sites of urban agriculture, e.g., community gardens, farms and school gardens, that have garnered more attention ${ }^{2,3}$. Taylor and Lovell ${ }^{2}$, for example, found that the total area of larger home gardens in Chicago visible in aerial images in Google Earth exceeded that of all other urban agriculture sites combined $\left(158,876\right.$ versus $\left.105,305 \mathrm{~m}^{2}\right)$. With the addition of smaller gardens not visible in aerial images, this number can be expected to be much higher. 
We define the 'urban home food garden' (UHFG) as a garden managed by a single household on owned, rented or borrowed land, either on the same property as the residence or on adjacent land such as a vacant lot, tree lawn or right of way. Outdoor home food gardening may occur in the ground, in raised beds or in containers on built surfaces. The UHFG may provide food - including vegetables, fruit and culinary herbs - for not only the household but also for the larger community through the gifting, sale or barter of garden production. The lack of research on UHFGs in the North is puzzling and may, we hypothesize, stem from multiple factors, including the very diversity of the UHFG and its functions and the relative inaccessibility of backyard UHGFs to researchers who wish to sample and study them ${ }^{7}$.

Our current research program seeks to address this gap in the literature - and ultimately to offer guidance to nongovernmental organizations (NGOs), policymakers and other researchers-by exploring the social-ecological or socio-natural effects of home food gardening using a mixed methods research approach. Our methodology combines qualitative social science methods (in-depth interviews and participant observation) with qualitative and quantitative natural science methods (botanical surveys, garden mapping, and the physical and chemical analysis of soil properties) as a way of developing a better understanding of the relationship between the lived experiences of gardeners and the biophysical characteristics and processes of their gardens.

Our research program is informed by the more extensive academic literature on community gardens in the Global North and home gardens in the South and rural North. Community gardens are reported to contribute to household and community food security, community development and resilience and the reproduction of ecological knowledge through communities of practice. Home gardens in the South also purportedly contribute to food security, subsidize household food budgets, enhance household nutrition, furnish urban livelihoods, and conserve crop and native plant biodiversity ${ }^{7}$. At a broad scale, we ask, do UHFGs in the North have these same effects? If so, how? Through what interactions of the human and the biophysical?

Based on a review of the literature on community gardens and on home gardens in the South and rural North, we have developed an extensive set of research questions and hypotheses about the effects or properties of home food gardens in the urban North, reported in a previous paper $^{7}$. In this paper, we begin to address a subset of these questions and hypotheses through an analysis of data from a study of home gardens in Chicago, IL. This work is ongoing; data were collected in the summer and fall of 2012 and 2013 from a purposive sample of 31 African American, Chinese-origin and Mexican-origin households with home gardens. In a third round of data collection in 2014, the sample will be expanded to include more gardeners, more ethnic groups and more neighborhoods, and research questions will focus on urban agrobiodiversity, including its cultural role and the processes through which it is maintained. Future publications will present an extended, comparative analysis of the dynamics of home gardening across groups.

\section{Study Site and Focal Populations}

The project focuses on three populations-African American, Chinese-origin and Mexican-origin households with gardens - in three areas on the south side of Chicago, IL. Covering more than $606 \mathrm{~km}^{2}$, Chicago is the third most populous city in the United States, with a current population of almost 2.7 million human inhabi$\operatorname{tants}^{8}$, a dramatic decline from a high of over 3.6 million in 1950. The study areas were selected based on the ethnic composition of their populations (Table 1). The majority of residents of Study Area 1 are African American; Study Area 2 has a large Chinese-origin population and encompasses Chicago's Chinatown, while the majority of residents of Study Area 3 are Latino, primarily of Mexican descent. (The neighborhoods constituting the three areas are not identified, to protect the confidentiality of study participants in this and future publications, and are identified in the rest of the paper as Study Area 1,2 or 3.) Previous research has revealed important differences in the spatial distribution of UHFGs in the city: single-plot vacant lot gardens are more prevalent in African American-majority neighborhoods, while on-lot garden density is greatest in neighborhoods with high proportions of Chinese immigrants ${ }^{2}$. Mexican-origin households were included as a focal population because persons of Mexican descent constitute the largest Latino group in the city.

\section{Methods}

A purposive sampling strategy was used because of the lack of research on UHFGs in the North. Smaller purposive samples and a mixed methods research approach employing qualitative methods from the social sciences permit the in-depth investigation of gardenrelated patterns and processes, garden-centered social networks and the meaning of garden-related practices from the perspective of the gardener. Such an approach can be a productive prelude to quantitative surveys with representative random samples, allowing the researcher to determine the lay of the land before embarking on a large-scale study.

The authors' dataset of larger UHFGs in Chicagodeveloped through manual aerial image analysis in Google Earth - was used initially to identify households with UHFGs in the selected areas. All households with 
Table 1. Characteristics of the study areas selected for a mixed methods study of African American, Chinese-origin and Mexicanorigin households with home food gardens in Chicago, IL.

\begin{tabular}{|c|c|c|c|}
\hline & $\begin{array}{c}\text { Study area } 1 \\
\text { (African American sample) }\end{array}$ & $\begin{array}{c}\text { Study area } 2 \\
\text { (Chinese-origin sample) }\end{array}$ & $\begin{array}{c}\text { Study area } 3 \\
\text { (Mexican-origin sample) }\end{array}$ \\
\hline \multicolumn{4}{|l|}{ Housing $^{1}(\%)$} \\
\hline Single family & $20-25$ & $25-30$ & $25-30$ \\
\hline Owner occupied & $30-35$ & $45-50$ & $45-50$ \\
\hline \multicolumn{4}{|l|}{ Income $^{l}$} \\
\hline Mean household income & $\$ 20-30,000$ & $\$ 40-50,000$ & $\$ 40-50,000$ \\
\hline$<$ Poverty level $(\%)$ & $40-45$ & $20-25$ & $20-25$ \\
\hline$<2 \times$ poverty level $(\%)$ & $65-70$ & $40-45$ & $50-55$ \\
\hline \multicolumn{4}{|l|}{ Race/ethnicity ${ }^{2}(\%)$} \\
\hline White, non-Hispanic & $0-5$ & $25-30$ & $5-10$ \\
\hline African American, non-Hispanic & $95-100$ & $0-5$ & $0-5$ \\
\hline Asian, non-Hispanic & $0-5$ & $45-50$ & $5-10$ \\
\hline Hispanic & $0-5$ & $20-25$ & $85-90$ \\
\hline Foreign born ${ }^{1}(\%)$ & $0-5$ & $30-35$ & $45-50$ \\
\hline Food insecure ${ }^{3}(\%)$ & $40-45$ & $15-20$ & $10-15$ \\
\hline
\end{tabular}

large UHFGs in these areas were contacted by mail, and non-responding households were visited in person. In addition, smaller food gardens were identified through fieldwork - by driving and walking up and down neighborhood streets and alleys - and were added to the recruitment effort. From each area, an ethnically homogeneous sample was selected. A screener was used to ensure that samples represented the targeted ethnic group and diverse family structures and included lower income households (those with a total gross household income of less than twice the US Poverty Guideline). Gardens of diverse types and sizes were also sought.

Data collection began in 2012 with ethnobotanical surveys. To characterize the ecological context of food gardens within the larger residential landscape, all cultivated plants on the lot were inventoried. Garden inventories and maps were updated during subsequent garden visits during the 2012 growing season. Two or three in-depth, hour-long interviews were conducted with the household's primary gardener, often in the garden itself, which permitted the interviewer to observe the gardener's interactions with both plants and people in the garden and with passersby on city streets, alleys and sidewalks. Repeated visits to gardens during the growing season permitted: (1) the establishment of rapport with gardeners from minority groups; (2) the documentation of seasonal changes in crop plant assemblages and other dynamic social or ecological processes; and (3) the collection of detailed information from gardeners on a wide range of topics, including gardening practices, participation in gardening activities, garden history, garden-centered social networks and personal history. The household's primary food preparer-who was often also the primary gardener-was also interviewed. For each household, three soil samples to a depth of $30 \mathrm{~cm}$ were collected systematically from each garden area once during the growing season, in August or September. The samples were analyzed for texture, nutrients, $\mathrm{pH}$, soil organic matter and heavy metals. The rate of water infiltration was measured in three locations in each garden area using a single ring infiltrometer. Gardens were reinventoried in the summer of 2013, and gardeners were reinterviewed, when possible, about changes in their garden since the previous year.

\section{Results and Discussion}

\section{Sample characteristics}

The socio-demographic characteristics of the 31 gardeners (10 Mexican-origin, 10 Chinese-origin and 11 African American) recruited for the study varied across ethnic groups (Table 2). As a whole, African American and Chinese-origin gardeners were older than Mexican-origin gardeners, who were more likely to have young children at home than the other two groups. The Mexican-origin and African American samples were roughly divided between men and women, while only one of the Chinese-origin gardeners was male. The majority of the African American gardeners (10 of 11) were homeowners and longtime residents of the neighborhood; duration of residence and home ownership were mixed for the other two groups. Because of the study's focus on ethnic gardeners and the greater popularity of gardening among older adults ${ }^{9}$, almost all sample members were internal or international migrants. Of the 11 African 
Table 2. Characteristics of the gardeners and gardens selected for a mixed methods study of African American, Mexican-origin and Chinese-origin households with home food gardens in Chicago, IL.

\begin{tabular}{|c|c|c|c|}
\hline & $\begin{array}{c}\text { Study area } 1 \\
\text { (African American sample) }\end{array}$ & $\begin{array}{c}\text { Study area } 2 \\
\text { (Chinese-origin sample) }\end{array}$ & $\begin{array}{c}\text { Study area } 3 \\
\text { (Mexican-origin sample) }\end{array}$ \\
\hline \multicolumn{4}{|l|}{ Gardener characteristics } \\
\hline Sample size & 11 & 10 & 10 \\
\hline Gender ratio (M:F) & $5: 6$ & $1: 9$ & $5: 5$ \\
\hline Race/ethnicity & African American & Chinese-origin & Mexican-origin \\
\hline Age range & Late 40 s to late $80 \mathrm{~s}$ & Late 40 s to early $80 \mathrm{~s}$ & Early 30 s to late $70 \mathrm{~s}$ \\
\hline Foreign born & $1(9 \%)$ & $9(90 \%)$ & $10(100 \%)$ \\
\hline Household income $<2 \times$ poverty level & $5(45.5 \%)$ & $3(30 \%)$ & $5(50 \%)$ \\
\hline \multicolumn{4}{|l|}{ Garden characteristics } \\
\hline Mean food production area & $61.7 \mathrm{~m}^{2}$ & $52.2 \mathrm{~m}^{2}$ & $40.4 \mathrm{~m}^{2}$ \\
\hline \multicolumn{4}{|l|}{ Location } \\
\hline Single family lot & $4(36.3 \%)$ & $3(30 \%)$ & $0(0 \%)$ \\
\hline Multifamily lot & $2(18.2 \%)$ & $6(60 \%)$ & $6(60 \%)$ \\
\hline Vacant lot & $5(45.5 \%)$ & $1(10 \%)$ & $4(40 \%)$ \\
\hline \multicolumn{4}{|l|}{ Plant diversity } \\
\hline Mean food plant richness (taxa/garden) & 16.3 & 14.4 & 8.6 \\
\hline Mean flowering plant richness (taxa/garden) & 17.7 & 4.4 & 6.3 \\
\hline
\end{tabular}

American gardeners, seven - between the ages of 61 and 87-had migrated to Chicago as teenagers or young adults from rural areas or small towns in three southern US states, Alabama, Arkansas and Mississippi, as part of the Great Migration of African Americans from the American South to North. Only one of the Chinese-origin gardeners was US born; the others were immigrants from southern China. All of the Mexican-origin gardeners grew up in towns or rural areas in central to southern Mexico.

\section{Garden typologies}

Garden location and structure varied across study areas (Table 2 and Fig. 1). As expected, vacant lot gardens were most common in Study Area 1. Of the 11 African American gardens, five occupied vacant lots, four of which were former building sites that were being gardened in usufruct $(n=2)$ or were owned $(n=2)$ by residents of adjacent buildings. The fifth lot had never been developed but had been owned and gardened continuously by the same family since the 1930s. The remaining six gardens were located in the backyards of single-family houses or 'family buildings', i.e., two or three flat buildings in which members of the same family occupy all apartments. Four of the gardens of Mexican-origin households were on vacant lots, all former building sites; one lot was owned by the gardener, and the other three lots were gardened in usufruct. In general, on-lot gardens in Study Area 3 occupied more marginal spaces - including front yards and fence lines - because the backyards of the multifamily buildings in which gardeners in the study resided are often shared, multifunctional spaces accommodating the needs of multiple households, often including small children. The gardens of Chinese-origin households exhibited a unique layered structure consisting of a ground layer of leafy crops overtopped by vigorous vining cropstypically winter or hairy melon (Benincasa hispida) and bitter melon (Momordica charantia) - supported by trellises constructed from found lumber and branches. Only one garden in the Chinese-origin sample was on vacant land, which was privately owned and was gardened in usufruct by a recent immigrant from China. The gardens of Chinese-origin households were located primarily in the backyards of single-family dwellings, multifamily buildings or family buildings, with secondary growing areas in front yards and side yards. Food production in front yards is more extensive in Chinatown than in any other neighborhood in Chicago, but front yard gardens may be less culturally acceptable outside the ethnic enclave. A Chinese-origin gardener living on an ethnically mixed block outside Chinatown reported that her nonChinese-origin neighbor objected to her front yard garden, characterizing it as messy.

\section{Properties and Effects of the Garden: An Evaluation of Hypotheses}

Below we present an evaluation of our hypotheses about the properties and effects of UHFGs in the Global North, based on our published review of the literature on community gardens and on home gardens in the South and rural North ${ }^{7}$.

\section{Hypothesis 1}

UHFGs make a substantial contribution to household food budgets and to community food systems. The contribution of home gardens to the local food system was difficult to determine quantitatively for two reasons. 

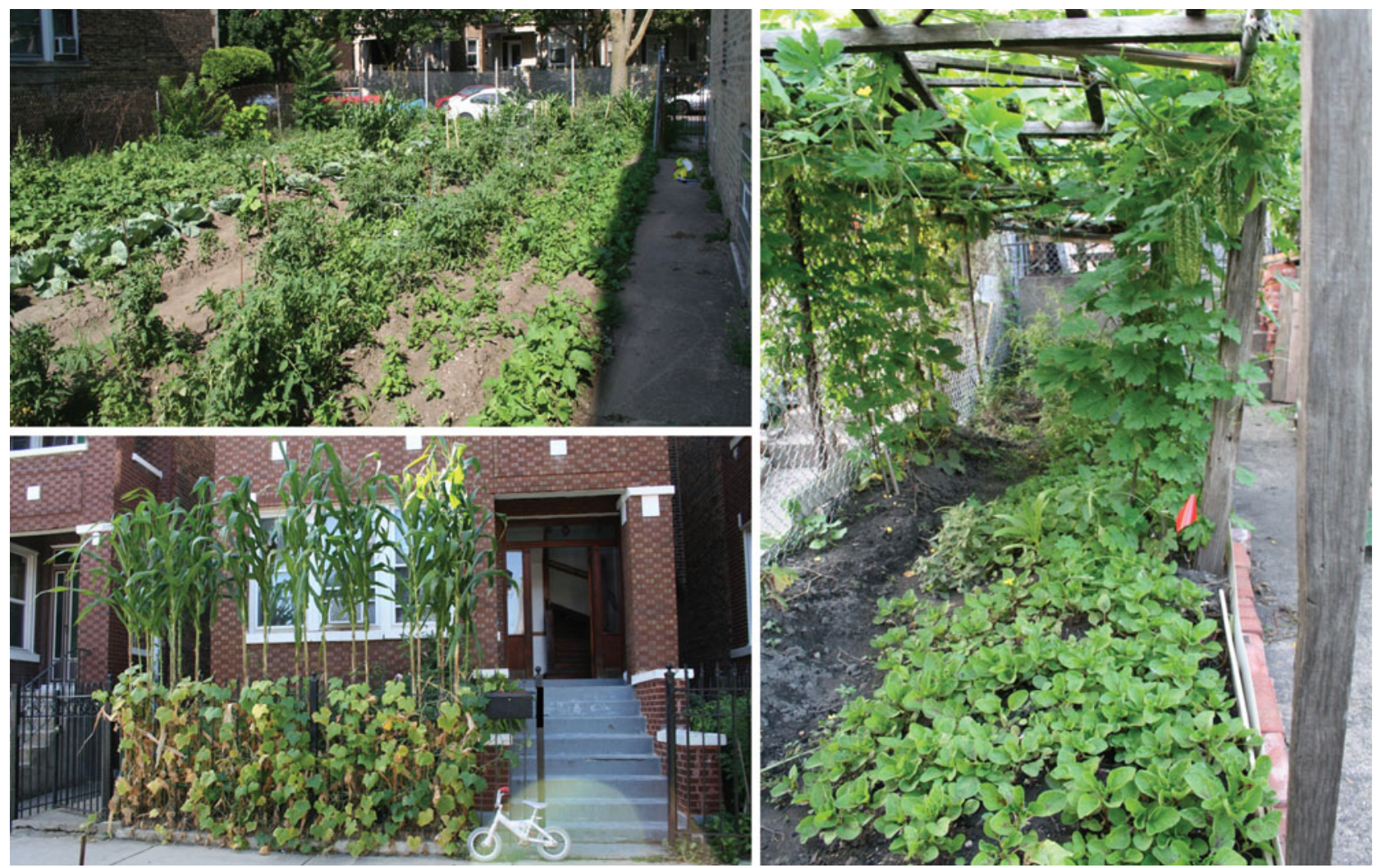

Figure 1. Examples of home food gardens of African American (top left), Mexican-origin (bottom left) and Chinese-origin (right) households in Chicago, IL.

Gardeners were asked to weigh all garden production during the 2012 growing season using a scale provided by the project. However, non-compliance was high, even among gardeners who appeared to be committed to the project. While garden production could be estimated from average yield statistics and the area or number of plants of each crop grown, as has been done in some studies of community gardens ${ }^{10}$, the resulting estimates are likely to be unreliable because of the large variation in growing conditions - and apparent plant productivity-observed in the sampled gardens. Soils were highly heterogeneous with widely varying nutrient levels. Furthermore, buildings and vegetation shaded all gardens but to varying degrees. Shading, the effects of which have not been investigated for most vegetable crop species, may have a large impact on yields ${ }^{11}$.

Although production could not be measured directly or estimated, average food garden area $\left(51.8 \mathrm{~m}^{2}\right)$ was relatively large compared to the area of a standard city lot $\left(290 \mathrm{~m}^{2}\right)$. Gardens ranged in size from 2.4 to $201.3 \mathrm{~m}^{2}$. Not surprisingly, given the large area of some gardens, some informants reported that their gardens made a substantial contribution to their household food budgets. One African American gardener, for example, claimed that she seldom bought vegetables during the growing season except for those she did not grow herself, including white potatoes, sweet potatoes and corn. Freezing produce from the garden was a common way for African American and Mexican-origin gardeners to preserve the harvest. For the former, preserving food they grew or purchased from farms outside the city and even stores represented a continuation of their parents' practice of putting up food for the winter in the rural South. One informant remarked, 'I never had to go hungry [as a child] because my father and mother, they were thrifty farmers, and they made sure during the summer they prepared for the winter'. Her neighbor added, 'Well when. . .chicken goes on sale or stuff...you'll be there [at the grocery store] because you don't want it to run out before you get there, and you buy more than what you need, maybe a twomonth supply for your family'.

\section{Hypothesis 2}

UHFGs contribute to local food systems beyond the household through the barter, gifting or sale of food. African American, Mexican-origin and Chinese-origin gardeners all said they shared food with neighbors, friends, family or even strangers. Only one gardener, of Mexican origin, reported selling produce-primarily pápalo (Porophyllum ruderale), a strongly aromatic herb popular in the Mexican state of Puebla - from his garden. In Chinatown, however, older women who had been observed working in their backyard gardens were also 
Table 3. Assemblages of unique food crops observed in the home gardens of African American, Mexican-origin and Chinese-origin households in Chicago, IL.

\begin{tabular}{|c|c|c|}
\hline African American & Mexican-origin & Chinese-origin \\
\hline $\begin{array}{l}\text { Black-eyed pea (Vigna unguiculata } \\
\text { subsp. unguiculata) } \\
\text { Collards (Brassica oleracea Acephala } \\
\text { Group) } \\
\text { Kale (Brassica oleracea Acephala } \\
\text { Group) } \\
\text { Mustard greens (Brassica juncea cvs) } \\
\text { Okra (Abelmoschus esculentus) } \\
\text { Poke sallet (P. americana) } \\
\text { Sweet potato (root) (Ipomoea batatas) } \\
\text { Turnip (top and root) (Brassica rapa } \\
\text { subsp. rapa) }\end{array}$ & $\begin{array}{l}\text { Amaranth, green (Amaranthus sp.) } \\
\text { Chilies-10+ varieties (Capsicum sp.) } \\
\text { Epazote (D. ambrosioides) } \\
\text { 'Frailes' (unidentified) } \\
\text { Hierba buena }(\text { Mentha spicata } \\
\quad \text { subsp. spicata) } \\
\text { Hoja santa }(\text { P. auritum) } \\
\text { Lambsquarters }(\text { C. album) } \\
\text { Pápalo }(P . \text { ruderale }) \\
\text { Sugarcane (Saccharum sp.) } \\
\text { Tropical corn }(\text { Zea mays subsp. mays) }\end{array}$ & $\begin{array}{l}\text { Amaranth, green and red (Amaranthus sp.) } \\
\text { Bitter melon (M. charantia) } \\
\text { Bunching onion (Allium fistulosum) } \\
\text { Chinese broccoli (Brassica oleracea Alboglabra } \\
\text { Group) } \\
\text { Chinese cabbage (Brassica rapa subsp. chinensis) } \\
\text { Chinese celery (Apium graveolens) } \\
\text { Chinese lettuce (Lactuca sativa cvs) } \\
\text { Chinese mustard (Brassica juncea cvs) } \\
\text { Chrysanthemum, edible (Glebionis coronaria) } \\
\text { Mustard spinach (Brassica rapa } \text { var. perviridis) } \\
\text { Garlic chives (Allium tuberosum) } \\
\text { Lemongrass (Cymbopogon sp.) } \\
\text { Malabar spinach (Basella alba) } \\
\text { Perilla (Perilla frutescens) } \\
\text { Pomegranate, dwarf (Punica granatum var. nana) } \\
\text { Sweet potato (leaves) (Ipomoea batatas) } \\
\text { Watercress (Nasturtium officinale) } \\
\text { White and yellow cucumber (Cucumis sativus cvs) } \\
\text { Winter/hairy melon (B. hispida) } \\
\text { Yardlong bean (Vigna unquiculata subsp. } \\
\text { sesquipedalis) } \\
\text { Yu choy sum (Brassica rapa var. parachinensis) }\end{array}$ \\
\hline
\end{tabular}

observed selling produce at a transient, informal market on a neighborhood street corner. When one of these women was later approached in her garden and asked about selling vegetables on the street corner, she denied doing so. Some home gardeners - particularly migrant gardeners - may be reluctant to admit to selling produce from their gardens, which is not explicitly permitted in the city's zoning ordinance, leading to the underreporting of sales. African American gardeners, though, seemed to find the idea of selling garden produce to be almost morally repugnant. As one gardener remarked, 'I'm so goodhearted, I just hate to sell anything like that. But there's money in that too. But the collard greens, if I go out there and pick them, I could sell them. But I just feel like I'm supposed to give them. I can't set no price for nobody'.

In Study Area 1, vacant lot gardens make a larger contribution to the local food system through gifting than do on-lot UHFGs. One gardener reported that 10-12 households received food from his vacant lot garden, while another reported she gave food-apparently substantial amounts - to anyone who asked, and even to those who did not: 'There was a group of ladies I was giving some to over on $\mathrm{P}_{-}$Street up there when I was taking the train to work. I walked through there every day, and one year we had so much I was like, I've got to give this stuff away because once you've harvested it you've got to do something with it. I had so many tomatoes and cucumbers I just put them in bags, put them in the truck, and said, hey y'all, get some of this'. For African American gardeners, sharing food from the garden may represent a continuation of Southern traditions of hospitality and community care, traditions which one elderly gardener referenced when discussing her chores on her parents' farm in Mississippi: 'We had about ten cows we had to milk every morning before we went to school. And people who didn't have cows, they would send gallon buckets up to where we were milking the cows, and my mother would say give this one a gallon of milk and that one a gallon of milk. She has four babies, and this one has so many. That's the way we would share with others'.

\section{Hypothesis 3}

Home gardens contribute to local food systems by making culturally acceptable foods readily accessible through culture-specific assemblages of plant species and varieties. (See Table 3.) African American gardeners from the rural American South often recalled fondly the gardens and diverse food crops their parents had grown: 'We would plant rows and rows of sweet potatoes, a whole field of sweet potatoes, just sweet potatoes. We raised peanuts and made our own peanut butter. All of the gardening that we did I could do. ..Corn, tomatoes, okra, string beans, all kinds of peppers, eggplant. We grew Brussels sprouts, squash, zucchini, white potatoes, onions, garlic; we had so many things - snow peas, three or four 
varieties of string beans actually'. Childhood memories of gardens influenced the composition of the food crop assemblages found in contemporary gardens. As one informant remarked when asked how he decided what to grow in his garden each year, 'I'm from Alabama, and during that time that I was down there my father used to grow everything, you know, like vegetables, greens, you name it, corn, cotton, you name it. My father he did it and I was raised up doing that and once I got up here [I got] into the garden'. The unique suite of crop plants found in these gardens support Southern foodways, or what one informant called 'country cooking,' which historically have been strongly influenced by African American cooks ${ }^{12}$. Collard, mustard and turnip greens were a prominent feature of these gardens, and some gardeners also allowed 'poke sallet' (Phytolacca americana), a weedy native perennial species spread by birds, to grow in their gardens to add to their greens.

Mexican-origin gardeners also grew a suite of unique crops, including chilies (Capsicum sp.) and herbs. The composition of that assemblage, like that of African American gardeners, was also influenced by ethnic foodways and the plants that migrant gardeners or their relatives had cultivated in Mexico. At least ten varieties of chilies were identified growing in gardens; the majority were common varieties purchased as plants from commercial sources [big box stores (e.g., Home Depot), supermarkets and a local flea market called 'Swap-ORama'] but others were grown from seed procured from friends or relatives in the neighborhood, in other US states and in Mexico. Herb plants integral to regional Mexican cooking were also grown in gardens, including pápalo ( $P$. ruderale), epazote (Dysphania ambrosioides), the tropical herb hoja santa (Piper auritum) and an unidentified species called 'frailes' by the gardener. Pápalo was grown from seed from multiple sources, including neighbors and friends and relatives in Mexico. Some gardeners grew tropical corn from seed imported from Mexico. This photoperiod-sensitive plant fails to bear ears in Chicago; instead, gardeners harvested its wide leaves to make a type of tamale known as a corunda popular in the Mexican state of Michoacán. Like the African American gardeners who harvested self-sown pokeweed from their gardeners, one Mexican-origin gardener allowed the weedy annuals green amaranth, or pigweed (Amaranthus sp.), and common lambsquarters (Chenopodium album), to grow in his garden for culinary use.

Gardeners of Chinese descent grew the largest assemblage of unique crop plants with origins in the Global South, including diverse leafy and vining crops integral to their layered gardens and successional, seasonal plantings. Bitter melon ( $M$. charantia) and winter or hairy melon (B. hispida) are key components of this culture-specific assemblage, with even small gardens accommodating these vigorously vining plants. Winter melon in particular was a prized food crop, cosseted by gardeners, who supported the large fruit with plastic bags and straw baskets, and occasionally stolen by non-gardeners, according to one informant.

\section{Hypothesis 4}

Gardens conserve (agro)biodiversity. A diversity of food crops minimizes the impact of crop failure in agricultural systems ${ }^{13}$, while flowering and other ornamental plants provide valuable ecosystem services-including pollination services and habitat for insect predators of plant pests ${ }^{14}$ - that potentially enhance the productivity and sustainability of those systems. Three measures of diversity were calculated to compare food crop and flowering plant diversity across study areas: richness (total number of taxa), taxa per square meter of total garden area (excluding lawn area) and similarity (the proportion of common crops between two sites or groups of sites). In aggregate, African American gardens demonstrated the highest food plant richness, with an average of 16.3 food crops per garden, and Mexican-origin gardens the lowest, with only 8.6 crops per garden. The average richness of Chinese-origin gardens was 14.4 crops. When normalized for total garden area, crop plant diversity was quite similar across all three groups of gardens: 0.38 versus 0.38 versus 0.30 crops $\mathrm{m}^{-2}$ for African American, Mexican and Chinese-origin gardens, respectively.

With a Sørensen-Dice similarity index $\left(S_{\mathrm{SD}}\right)$ of 0.47 , the aggregate food crop assemblages of African American and Mexican-origin gardens were more similar to each other than either was to the aggregate crop plant assemblage of Chinese-origin gardens $\left(S_{\mathrm{SD}}=0.21\right.$ for both comparisons). Surprisingly, gardens in Study Area 1 , the most economically disadvantaged area in the study, exhibited the highest diversity of ornamental flowering plants, with an average of 17.7 species per garden compared to 4.4 and 6.3 species per garden in the Chinese- and Mexican-origin gardens, respectively. The average number of flowering species per square meter of total garden area was almost equal in the African American and Mexican-origin gardens, 0.49 and 0.51, respectively, and much lower in the Chinese-origin gardens, 0.13 . The implications of low floral diversity for the productivity of the gardens of Chinese-origin households warrant further investigation.

Although we attempted to characterize food plant diversity at the variety level, gardeners often could not remember what varieties they had planted and appeared to make little or no distinction at the infraspecific (within species) level. The following exchange was typical of discussions about crop varieties:

Interviewer: What kind of carrots do you grow?

Informant: I don't know. Do you know when I buy them I just buy them.

Interviewer: How do you pick out which ones?

Informant: The first pack I see I just buy them.

Across gardens, infraspecific diversity appeared to be low. Most African American gardeners, for example, 
reported planting one variety of collards, 'Georgia', and a handful of conventional tomato varieties, including 'Beefsteak', 'Early Girl', 'Roma', 'Better Boy' and 'Big Boy'. Mexican-origin gardeners planted the same tomato varieties as African American gardeners. The infraspecific diversity of cross-pollinating Chinese vegetable crops grown from saved seed, such as winter gourd and bitter melon, could not be determined from the data collected. Differentiating between the varieties grown in home gardens would require phenotypic evaluation in a common garden or genomic analysis.

Low infraspecific diversity has implications for the overall productivity of the UHFG. With a narrow genetic base, the food crops grown in urban gardens may be vulnerable to disturbances such as disease outbreaks or, with climate change, highly variable weather conditions. Urban growing environments are also highly heterogeneous ${ }^{11}$ and are often of marginal quality compared to agricultural land outside the city. Because of a lack of research on the performance of crop plants in these environments, it is unknown whether the varieties currently grown by urban gardeners are equally productive across environments or whether gardeners might be better served by varieties adapted to particular niches in the urban landscape, e.g., shady gardens, gardens with well drained or poorly drained soils.

\section{Hypothesis 5}

Diverse factors and processes influence garden plant richness and, consequently, the contributions of the UHFG to urban systems. While some quantitative studies suggest landscape diversity could be greater for affluent households (a so-called 'luxury effect' of access to greater resources) ${ }^{15}$, in our finer grained qualitative study we found that other factors and processes contribute to the development and maintenance of diversity in the home food garden and its landscape context. The unpredictability of environmental conditions and crop plant performance, for example, may prompt gardeners to diversify the crops they grow. As one African American gardener - who had earlier commented on the unpredictability of Chicago's weather-remarked, 'Every year you're not going to have a good crop for certain things but you just keep on because you will get something, and so this year looks like I'm going to have a good crop of tomatoes'. The African American gardeners with the highest ornamental flowering plant diversity in their gardens acquired their plants from neighbors, fellow garden club members, plant salvage or plant 'giveaways' sponsored by NGOs or government agencies. One African American gardener with few economic resources - and no automobile - but high social capital was particularly adept at mobilizing that capital to enlarge her collection, even recruiting the drug dealer across the street to ferry her to and from a plant giveaway in his luxury car. African American gardeners' longer duration of residence in their homes may also account for the high diversity of ornamental plants in their gardens, allowing them to accumulate perennial species over 40 or more years in some cases.

\section{Hypothesis 6}

Gardens rely heavily on external inputs, undermining their sustainability. While Kortright and Wakefield ${ }^{16}$ found that most home food gardeners in their Torontobased study practiced organic cultural methods - possibly an effect of provincial restrictions on cosmetic pesticide use - that was not the case in our study. The use of synthetic fertilizers, including water-soluble fertilizers such as Miracle-Gro ${ }^{\mathrm{TM}}$, was common, and the use of synthetic pesticides purchased from big box stores or local garden centers was not uncommon. One African American gardener, for example, reported applying a preemergent herbicide and fertilizer to his garden each spring. Even those gardeners who did not use synthetic fertilizers applied bagged organic matter to their gardens, e.g., composted cow manure, purchased at supermarkets or big box stores. No gardeners used cover crops. Only one had a compost pile. Gardeners did practice other passive forms of nutrient cycling, including burying kitchen and garden waste in their gardens. However, many gardeners reported throwing garden waste in the municipal trash at the end of the growing season. Soil testing guided the application of neither fertilizer nor organic matter. Not even the sole master gardener in the study sample had ever had her soil tested for nutrients.

Gardeners relied heavily on other inputs external to the local community, including water, seeds and plants, though Chinese-origin gardeners were less reliant on external inputs of seeds and plants than African American or Mexican-origin gardeners. The majority of the crops they grew were direct seeded, obviating the need for purchased plants, and they saved seeds from crops such as bitter melon, long bean and winter melon. While seemingly benign, the use of commercial seeds and plants may have negative social and ecological consequences. As Calvet-Mir et al ${ }^{17}$ found in rural villages in Vall Fosca in the Catalan Pyrenees of Spain, reliance on the market for seeds and plants can lead to reduced agrobiodiversity, a loss of social-ecological knowledge and the breakdown of social networks. It can also stymie the development of locally adapted varieties. At the same time, the ready availability of commercial seeds and plants may be enabling for urban gardeners who may lack the time, land or horticultural knowledge to produce their own seeds or transplants ${ }^{7}$.

\section{Hypothesis 7}

Gardening practices and external inputs influence the chemical and physical properties of garden soils, which may be a source of ecosystem services and disservices. Urban garden soils are highly heterogeneous not only because of 
disturbance from initial development and construction but also because of the activities of gardeners. Like garden flora, garden soils were assembled from diverse sources. Gardeners filled the foundations of demolished buildings with materials scavenged from alleyways. They augmented the 'native' soil of their gardens with soil, compost and manure purchased in bulk or as bagged goods. They reported scavenging soil and organic matter from locations including an old stable, a forest preserve, construction sites and even the grounds of a former tuberculosis sanitarium.

They also applied organic and synthetic fertilizers to their soils, and in the majority of gardens surveyed nutrients were not limiting. Phosphorus and potassium levels often far exceeded levels required for optimal plant growth. While $25 \mathrm{ppm}$ of phosphorus is an optimum level for vegetable gardens ${ }^{18}$, sample concentrations ranged from 36 to $1076 \mathrm{ppm}$ and averaged $263 \mathrm{ppm}$ across the 31 gardens in the study. Concentrations of potassium ranged from 40 to $1236 \mathrm{ppm}$ and averaged $231 \mathrm{ppm}$; $200 \mathrm{ppm}$ is the recommended level for vegetable gardens ${ }^{18}$. Phosphorus and potassium levels were significantly higher in Chinese-origin gardens than in Mexican-origin or African American gardens, and the phosphorus and potassium concentrations of samples from the former gardens were strongly correlated $\left(R^{2}=0.63\right)$, suggesting a common source of both nutrients in these gardens, most likely synthetic fertilizers. We hypothesize that Chinese-origin gardeners believe that very high levels of soil nutrients are necessary to sustain their apparently highly productive gardens. However, at high levels, phosphorus concentrations may inhibit plant growth. In addition, phosphorus, which has low solubility in water but adsorbs strongly to soil particles, may pollute stormwater through the erosion of those particles from bare garden soils. Stormwater pollution from gardens may be particularly problematic in Chinatown, which has a high proportion of impervious surface and where food gardens appear to constitute the largest pervious land cover type.

Gardeners' practices may mitigate the environmental impact of overfertilization by improving stormwater infiltration in garden soils, an important ecosystem service. Infiltration rates for urban soils have been reported to be highly variable ${ }^{19}$, and initial infiltration rates for our Chicago garden soils ranged from 0.07 to $30.0 \mathrm{~cm} \mathrm{~min}^{-1}$. On average, however, rates were quite high across all three groups of gardens, ranging from $4.3 \mathrm{~cm} \mathrm{~min}^{-1}$ in Chinese-origin gardens to $5.4 \mathrm{~cm} \mathrm{~min}^{-1}$ in the African American gardens. Gardeners' application of organic matter and frequent tillage of garden soils, both of which increase soil porosity, may account in part for these high average infiltration rates. The percentage of soil organic matter was relatively high across all garden sites, ranging from $2.9 \%$ to $13.4 \%$ with an average value of $6.4 \%$. Almost all gardens $(n=29)$ were weed and mulch free, with the top stratum of bare soil frequently disturbed by hand cultivation or rototilling. Several African American gardeners planted their crops on bare ridges of soil and reported hoeing soil from the area between crop rows onto the ridges over the course of the growing season, practices they traced to their Southern roots. While high infiltration rates may mitigate the impact of excess garden nutrients on stormwater quality by reducing the erosion of phosphorus-laden soil particles from bare garden soil, they also potentially increase the leaching of water-soluble nutrients such as nitrates into groundwater.

\section{Hypothesis 8}

Soil contamination could pose a threat to food safety and human health and undermine the UHFG's contribution to local food systems. None of the gardeners in our study had previously tested their soil for lead (or for nutrients or other heavy metals), and only two gardeners were cognizant of the potential health risk posed by contaminated soil. Only one gardener employed compost-filled raised beds for food production, a common mitigation technique in community gardens. All other gardens were in ground, in 'native', unmitigated soil. EPA lead levels varied widely across garden soil samples, from 60 to $992 \mathrm{ppm}$, but study area averages were uniformly high, between 337 and $363 \mathrm{ppm}$. (Concentrations of other heavy metals were highly correlated with lead levels.) Those averages were much lower than the mean value of $2180 \mathrm{ppm}$ reported by Shinn et al. $^{20}$ for 62 residential properties in a four-block area of Chicago, comparable to the mean value of $395 \mathrm{ppm}$ reported by Kay et al. ${ }^{21}$ for 57 samples from city-owned land and higher than the mean value of $224 \mathrm{ppm}$ reported by Witzling et al. ${ }^{22}$ for inground community garden plots in the city. The risk that lead-contaminated soil poses to the health of gardeners and their families is uncertain, with a wide range of maximum safe levels proposed in the literature ${ }^{22}$. Research suggests that the uptake of soil lead by vegetable crops may be weak ${ }^{23,24}$. Inhalation or consumption of contaminated soil particles, though, represents another exposure pathway. For $27 \%$ of the soil samples collected in our study, the lead concentration exceeded the EPA's hazard threshold of $400 \mathrm{ppm}$ of lead in bare soil in children's play areas ${ }^{25}$. The frequent cultivation of garden soil that we observed may therefore result in increased exposure of gardeners and their families to lead in the form of contaminated dust or soil particles directly ingested or adhering to garden produce.

\section{Conclusion}

Our work with African American, Mexican-origin and Chinese-origin gardeners in Chicago suggests that UHFGs in the Global North share a number of beneficial effects that have been reported in the literature for 
community gardens and for home gardens in the South. UHGFs in the North strengthen community self-reliance and resilience by contributing produce from unique, culture-specific assemblages of food plants to local food systems through the gifting and, to a lesser extent, the sale of food. Gardens are also sites of cultural reproduction, which may enhance resilience at the household level, where values, practices and ethnic identity are resources that help individuals cope with crisis and trauma ${ }^{26}$. We found significant differences in gardener demographics, gardening practices, garden morphology, flowering plant diversity and food plant assemblages across ethnic groups. Future publications based on the data examined in this report will explore these differences and their implications for urban socionatural systems in greater detail.

UHFGs in the Global North may also serve as reservoirs of (agro)biodiversity. In this study we found that a number of processes and factors other than household income - the so-called luxury effect of greater access to resources - contributed to the biodiversity of residential lots with food gardens. However, while overall plant diversity was high in some gardens, particularly African American gardens, floral diversity was low in others, notably the gardens of Chinese-origin households, and many gardeners grew a narrow range of commercial cultivars from purchased seed or plants. Low flowering and crop plant diversity may have negative implications for garden productivity and the contribution of the UHFG to local food systems. At the same time, ethnic gardeners - particularly Chinese-origin gardeners - who save the seeds of open-pollinated varieties of traditional crop plants may be preserving agrobiodiversity with origins in the Global South. Measuring the infraspecific diversity of these crops, however, requires research beyond the scope of the present project.

Although most of the impacts of gardening were positive, we found that the gardeners in this study relied heavily on external inputs, including seeds, plants, water, organic matter and synthetic fertilizers and pesticides to produce food. The sustainability of these inputs is questionable and their use reduces household and community self-reliance. While gardeners compost some garden waste on site, much of it enters the municipal waste stream, contributing to regional landfills and leaving open nutrient cycles within the garden. Gardeners import nutrient-rich compost and fertilizers from outside the garden, and a lack of careful nutrient management may contribute to urban stormwater pollution. Furthermore, contamination of unmitigated home garden soils poses a potential threat to the health of gardeners and their families, though in the case of lead the ingestion or inhalation of contaminated soil particles may present a greater risk to human health than the uptake of lead by crop plants.

Clearly, UHFGs in the Global North have the potential to make a substantial contribution to urban systems at the level of the household and larger scales. Our research, however, suggests a need for material support and outreach to fully realize that potential. Access to material resources was a concern for gardeners in our study and may be an even greater issue for the neighborhood residents not included in this study who wish to garden but do not. Some gardeners in the study expressed an interest in acquiring more land for recreational gardening or for small-scale farming, which is currently not permitted in residential districts in Chicago. Others remarked on the high cost of seeds, plants and other gardening supplies and lamented the loss of public or private distribution programs of free vegetable seeds and plants.

Gardeners in our study demonstrated an interest in learning more about gardening. While their practices were informed by traditional agroecological knowledge associated with their place of origin, those practices were malleable. They were further shaped by practical knowledge gained through gardening in Chicago, by the popular media, and by their interactions with gardening friends and neighbors and staff at garden centers and big box stores. Gardeners also frequently had questions for researchers about pest control, nutrient management and the cultivation of particular crop plants. All of these findings suggest a need for and receptiveness to increased outreach to home gardeners-particularly underserved minority gardeners - by the extension and research communities.

In addition to material and informational resource limitations, the biophysical environment potentially constrains the productivity and sustainability of urban production systems ${ }^{27}$ including the home garden. Our research suggests that home gardeners could make valuable and willing partners in designed experiments ${ }^{28}$ and participatory research programs with the goal of developing culturally appropriate, productive, sustainable and safe models of food production for the home garden. Gardeners in our study were curious about ecological processes in the food garden, formulating and testing hypotheses about garden phenomena, such as the failure of plants to thrive. With their inquisitiveness about the biophysical world and knowledge of urban food production practices, gardeners such as these could serve as co-researchers in universitysponsored research projects. As co-researchers, gardeners would help shape research goals and methods, and collect data in their own home gardens, which would function as experimental replicates in, for example, multilocational field trials of new food plant cultivars bred for urban conditions.

Through these strategies - increased outreach and material support for home gardening and participatory research programs addressing the social and biophysical limitations to urban food production - the promise of home food gardens as a source of social and ecological benefits can be fully realized in the urban Global North. 


\section{References}

1 Guitart, D., Pickering, C., and Byrne, J. 2012. Past results and future directions in urban community gardens research. Urban Forestry \& Urban Greening 11:364-373.

2 Taylor, J.R. and Lovell, S.T. 2012. Mapping public and private spaces of urban agriculture in Chicago through the analysis of high-resolution aerial images in Google Earth. Landscape and Urban Planning 108(1):57-70.

3 Smith, V.M., Greene, R.B., and Silbernagel, J. 2013. The social and spatial dynamics of community food production: A landscape approach to policy and program development. Landscape Ecology 28(7):1415-1426.

4 Schupp, J.L. and Sharp, J.S. 2012. Exploring the social bases of home gardening. Agriculture and Human Values 29 (1):93-105.

5 Airriess, C.A. and Clawson, D.L. 1994. Vietnamese market gardens in New Orleans. Geographical Review 84(1):16.

6 Gray, L., Guzman, P., Glowa, K.M., and Drevno, A.G. 2014. Can home gardens scale up into movements for social change? The role of home gardens in providing food security and community change in San Jose, California. Local Environment 19(2):187-203.

7 Taylor, J.R. and Lovell, S.T. 2014. Urban home food gardens in the Global North: Research traditions and future directions. Agriculture and Human Values 31(2):285-305.

8 U.S. Census Bureau 2011. U.S. Census Bureau delivers Illinois' 2010 Census population totals 2011. Available at Web site http://2010.census.gov/news/releases/operations/ cb11-cn31.html (cited November 21, 2011).

9 National Gardening Association. 2009. The impact of home and community gardening in America 2009. Available at Web site http://www.gardenresearch.com/files/2009-Impactof-Gardening-in-America-White-Paper.pdf (accessed March 15, 2012).

10 Vitiello, D. and Nairn, M. 2009. Community Gardening in Philadelphia: 2008 Harvest Report. University of Pennsylvania Planning and Urban Studies, Philadelphia.

11 Wagstaff, R. and Wortman, S.E. 2014. Crop physiological response across the Chicago metropolitan region: Developing recommendations for urban and peri-urban farmers in the North Central US. Renewable Agriculture and Food Systems (online ahead of print):1-7.

12 Harris, J.B. 2011. High on the Hog: A Culinary Journey from Africa to America. Bloomsbury Publishing, New York, USA.

13 Thrupp, L.A. 2000. Linking agricultural biodiversity and food security: The valuable role of agrobiodiversity for sustainable agriculture. Internal Affairs 76(2):283-297.

14 Andersson, E., Barthel, S., and Ahrné, K. 2007. Measuring social-ecological dynamics behind the generation of ecosystem services. Ecological Applications 17(5):1267-1278.

15 Cook, E.M., Hall, S.J., and Larson, K.L. 2012. Residential landscapes as social-ecological systems: A synthesis of multi-scalar interactions between people and their home environment. Urban Ecosystems 15(1):19-52.
16 Kortright, R. and Wakefield, S. 2011. Edible backyards: A qualitative study of household food growing and its contributions to food security. Agriculture and Human Values 28(1):39-53.

17 Calvet-Mir, L., Calvet-Mir, M., Molina, J.L., and ReyesGarcía, V. 2012. Seeds exchange as an agrobiodiversity conservation mechanism: A case study in Vall Fosca, Catalan Pyrenees, Iberian Peninsula. Ecology and Society 17(1):29.

18 Rosen, C.J., Bierman, P.M., and Eliason, R.D. 2008. Soil Test Interpretations and Fertilizer Management for Lawns, Turf, Gardens, and Landscape Plants. University of Minnesota Extension, St Paul, MN.

19 Pitt, R. and Lantrip, J. 2000. Infiltration through disturbed urban soils. In W. James (ed.). Applied Modeling of Urban Water Systems, Proceedings of the Conference on Stormwater and Urban Water Systems Modeling, February 1999, Toronto, Ontario. CHI, Guelph, Ontario, Canada. p. 1-22.

20 Shinn, N.J., Bing-Canar, J., Cailas, M., Peneff, N., and Binns, H.J. 2000. Determination of spatial continuity of soil lead levels in an urban residential neighborhood. Environmental Research 82(1):46-52.

21 Kay, R.T., Arnold, T.L., Cannon, W.F., and Graham, D. 2008. Concentrations of polycyclic aromatic hydrocarbons and inorganic constituents in ambient surface soils, Chicago, Illinois: 2001-2002. Soil \& Sediment Contamination 17(3):221-236.

22 Witzling, L., Wander, M., and Phillips, E. 2011. Testing and educating on urban soil lead: A case of Chicago community gardens. Journal of Agriculture, Food Systems, and Community Development 1(2):167-185.

23 Attanayake, C.P., Hettiarachchi, G.M., Harms, A., Presley, D., Martin, S., and Pierzynski, G.M. 2014. Field evaluations on soil plant transfer of lead from an urban garden soil. Journal of Environmental Quality 43(2):475-487.

24 McBride, M.B., Simon, T., Tam, G., and Wharton, S. 2013. Lead and arsenic uptake by leafy vegetables grown on contaminated soils: Effects of mineral and organic amendments. Water, Air, Soil Pollution 224(1):1-10.

25 Environmental Protection Agency. 2001. Lead. Identification of dangerous levels of lead. Final rule, 40 CFR Part 745. EPA, Washington, DC.

26 McCubbin, L.D. and McCubbin, H.I. 2005. Culture and ethnic identity in family reslience. In M. Ungar (ed.). Handbook for Working with Children and Youth: Pathways to Resilience across Cultures and Contexts. Sage Publications, Thousand Oaks, CA. p. xxxix, 511.

27 Wortman, S.E. and Lovell, S.T. 2013. Environmental challenges threatening the growth of urban agriculture in the United States. Journal of Environmental Quality 42 (5):1283-1294.

28 Felson, A.J. and Pickett, S.T. 2005. Designed experiments: New approaches to studying urban ecosystems. Frontiers in Ecology and Environment 3(10):549-556. 